\title{
Numerical study of the electrochemical exfoliation of graphite
}

\author{
Ali A. Muhsan ${ }^{1} \cdot$ Khalid Lafdi $^{1}$ \\ (c) Springer Nature Switzerland AG 2019
}

\begin{abstract}
In this study, graphene was prepared using electrochemical exfoliation method. Numerical study of the exfoliation process of graphite was carried out using COMSEL Multiphysics 5. The homemade graphene was characterized using various microscopy, spectroscopy and X-ray diffraction techniques. The prepared graphene oxide consists of few layers of graphene. The numerical study showed that the concentration of sulfate anions was transported through graphite rod in the range $\left(9.77 \times 10^{-7}-4.58 \times 10^{-5}\right) \mathrm{mol} / \mathrm{m}^{3}$ and stresses distribution which resulted from sulfate anions interaction along the graphite rod in the range $\left(3.43 \times 10^{-8}-5.77 \times 10^{-7}\right) \mathrm{N} / \mathrm{m}^{2}$.
\end{abstract}

Keywords Graphene - Electrochemical exfoliation · COMSOL Multiphysics

\section{Introduction}

Graphene, a two-dimensional honeycomb sp ${ }^{2}$ carbon lattice, shows a potential use in the next-generation of electronic devices [1, 2], composite materials [3], energy storage and conversion [4], drug delivery, sensor and catalysis due to its extraordinary properties $[5,6]$. Graphene has a high charge carrier mobility $\left(2 \times 10^{5} \mathrm{~cm}^{2} / \mathrm{Vs}\right)[7]$, high thermal conductivity (greater than $2000 \mathrm{~W} / \mathrm{m} . \mathrm{K}$ ) [8], exceptional young's modulus ( $1 \mathrm{TPa})[9]$, large specific theoretical surface area $\left(2630 \mathrm{~m}^{2} / \mathrm{g}\right)[10]$ and high transparency $97.7 \%[11]$.

Since the graphene discovery in 2004, many fabrication methods were explored. Graphene could be prepared by exfoliation, epitaxial growth, chemical vapor deposition (CVD), solvent- and/or surfactant assisted liquid-phase exfoliation of graphite, and the thermal/chemical reduction of graphene oxide $[12,13]$. Electrochemical exfoliation of graphite has attracted specific attention due to its simplicity, fast, controllable and environmentally friendly in producing high-quality graphene [14-16]. It involved shear deformation of graphite electrode by applying an electrical potential either anodic polarization to oxidize the graphite rod to produce graphene oxide or cathodic polarization to obtain graphene then allowed the cations or anions to intercalate between graphene layers to form graphite intercalated compounds (GICs) [17]. Then as the process evolves into exfoliation stage, graphene is produced. The electrolyte played a major role in the electrochemical exfoliation process due to its influence on the composition, structure and properties of resulting graphene sheets [18]. Different kinds of electrolytes have been used, including ionic liquid $[19,20]$, high molecular polymer [21], polar solvent [22], surfactant [23] and inorganic solution [24-26]. Among them $\mathrm{H}_{2} \mathrm{SO}_{4}$ solution, has been more frequently investigated because of its high yield, which is essential for the practical use of graphene. The quality of graphene is strongly depended on the potential applied as well as by the electrolyte employed. The use of high voltages facilitates the generation of oxygen groups on the exfoliated graphene as well as structural damage. For this reason, the application of negative potentials under cathodic conditions in the presence of positive intercalation ions such as tetraalkylammonium cations was attempted to avoid the formation of oxygen functionalities and to obtain graphene of better quality $[27,28]$. Abdelkader et al. [29] prepared graphene via cathodic exfoliation of

Ali A. Muhsan, muhsana1@udayton.edu; Khalid Lafdi, klafdi1@udayton.edu|'Department of Chemical and Materials Engineering, University of Dayton, Dayton, $\mathrm{OH} 45469$, USA.

SN Applied Sciences (2019) 1:276| https://doi.org/10.1007/s42452-019-0296-8 
graphite in dimethyl sulfoxide containing lithium and triethylammonium $\left(\mathrm{Et}_{3} \mathrm{NH}^{+}\right)$. They obtained few layers of graphene with a diameter ranging from 1 to $20 \mu \mathrm{m}$ without using sonication or centrifugation processes. Kakaei and Zhiani [30] prepared graphene nanosheets through electrochemical exfoliation using Urea choline chloride/water solution at (1:1) ratio then fabrication composite material consisted of platinum nanoparticles/graphene nanosheets rod to enhance methanol oxidation of fuel cell. They stated that the prepared composite material is a promising method for improving efficiency of direct methanol fuel cells. Huang et al. [31] utilized two-steps electrochemical exfoliation using $\mathrm{NaOH}$ to expand graphite foil and $\mathrm{H}_{2} \mathrm{SO}_{4}$ for the exfoliation. They reported that the two-step electrochemical exfoliation produced high quality graphene. Kakaei and Hasanpour investigated the role of cetyltrimethylammonium bromide (CTAB) as an electrolyte on the mechanism of electrochemical exfoliation of graphite. They reported that the CTAB intercalate into the graphite rod then followed by exfoliation process to produce graphene [32]. Ambrosi and Pumera [33] studied electrochemical exfoliation of graphite using three different electrolytes $\mathrm{H}_{2} \mathrm{SO}_{4}, \mathrm{Na}_{2} \mathrm{SO}_{4}$, and $\mathrm{LiClO}_{4}$. They reported that graphene produced in $\mathrm{H}_{2} \mathrm{SO}_{4}$ had higher density of defects than other electrolytes. However, $\mathrm{LiClO}_{4}$ seems very suitable electrolyte to prepare graphene oxide. Because of a high amount of oxygen functionalities, the grapherne oxide can be used as additives for fabrication of polymer-based nanocomposite. Najafabadi et al. [34] used iso-molded graphite as anode and a novel electrolyte that consist of ionic liquids and acetonitrile (1:50 vol. IL/solvent ratios) for graphene production. They showed that higher rate of graphene exfoliation in BMPyrr BTA/acetonitrile solution as compared to other ionic liquids because of large oxygenated BTA anions. However, few papers were published depicting the exfoliation mechanism of graphite. Shinde et al. [35] studied electrochemical exfoliation of graphite by shear assisting to exfoliate graphene and simulated this process using COMSOL Multiphysics. They stated that the shear rate played a main role on the yield, thickness and quality of exfoliated graphene. Pupysheva et al. [36] simulated graphene nanoplatelets exfoliation via ultrasonication process using gaussian and universal force field. They reported that a nonresonant locking mechanism involving surfactant molecules is shown to be a feasible exfoliation mechanism through direct ultrasonication. Yang and Liu [37] studied the mechanism of liquid exfoliation of graphene using molecular dynamics. They reported that the slidingaway mechanism is played a main role for liquid exfoliation process because the surfactant-graphene interaction is maximized which is critical to the separation process. Shao et al. [38] studied exfoliation mechanism of graphite for modified Hummers method and they stated that the layer spacing of graphene sheets $3.334 \AA$ calculated by molecular dynamics simulations coincided with the X-ray diffraction results. Gai et al. [39] exfoliated graphite using rotor-stator in different solvents (supercritical $\mathrm{CO}_{2}$, water, NMP) and they used computational fluid dynamics to simulate exfoliation mechanism. They stated that the volume of the active region, which is the gap between the stator and the rotor, and the effective exfoliation time influenced on graphene yield. Fu and Yang [40] simulated the liquid phase exfoliation of graphite using different solvents, N-methyl pyrrolidine (NMP), dimethyl sulfoxide (DMSO) and water via molecular dynamic simulation. They stated that NMP and DMSO had stronger affinity with graphene surface and parallel exfoliation of graphene is preferred rather than vertical exfoliation due to it required less external power. In this work, we prepared graphene oxide via anodically electrochemical exfoliation method and we used COMSOL Multiphysics 5 to simulate this phenomenon employing transport of diluted species and fluid-structure interaction physics for numerical study of this process.

\section{Experimental procedure}

The electrochemical exfoliation cell consisted of a graphite electrode which used as working electrode (anode) and platinum wire (cathode) worked as a counter electrode and the electrolyte consists of $0.1 \mathrm{M}$ diluted sulfuric acid. The anodic exfoliation of graphite carried out by utilizing power supply through applying an electrical potential to the graphite electrode $10 \mathrm{~V}$ at room temperature. Anodic potential oxidized the graphite rod and allowing for sulfate anions $\left(\mathrm{SO}_{4}{ }^{2-}\right)$ to intercalate through interlayer spacing of graphite to exfoliate graphene oxide. The exfoliated graphene collected and washed using deionized water many times to remove sulfate ions throughout vacuum filtration using filtration paper then the collected exfoliated graphene dried in oven at $60^{\circ} \mathrm{C}$. Figure 1 shows the experimental setup for the electrochemical exfoliation.

The reactions occurred during the electrochemical exfoliation process are listed below.

$$
\begin{aligned}
& 2 \mathrm{H}_{2} \mathrm{O} \rightarrow 2 \mathrm{H}^{+}+\mathrm{O}_{2}+2 \mathrm{e}^{-} \\
& \mathrm{C}_{\mathrm{s}}+2 \mathrm{H}_{2} \mathrm{O} \rightarrow 2 \mathrm{CO}+4 \mathrm{H}^{+} \\
& \mathrm{H}_{2} \mathrm{SO}_{4} \rightarrow 2 \mathrm{H}^{+}+\mathrm{SO}_{4}^{2-} \\
& \mathrm{C}_{\mathrm{b}}^{+}+\mathrm{SO}_{4}^{2-} \rightarrow \mathrm{C}^{+}\left(\mathrm{SO}_{4}^{2-}\right) \\
& \left.\mathrm{C}^{+}\left(\mathrm{SO}_{4}^{2-}\right) \rightarrow \mathrm{C} \text { (graphene }\right)+\mathrm{SO}_{2}+\mathrm{O}_{2}
\end{aligned}
$$

where $C_{s}$ and $C_{b}$ are surface of graphite and graphite bulk respectively.

\section{SN Applied Sciences}




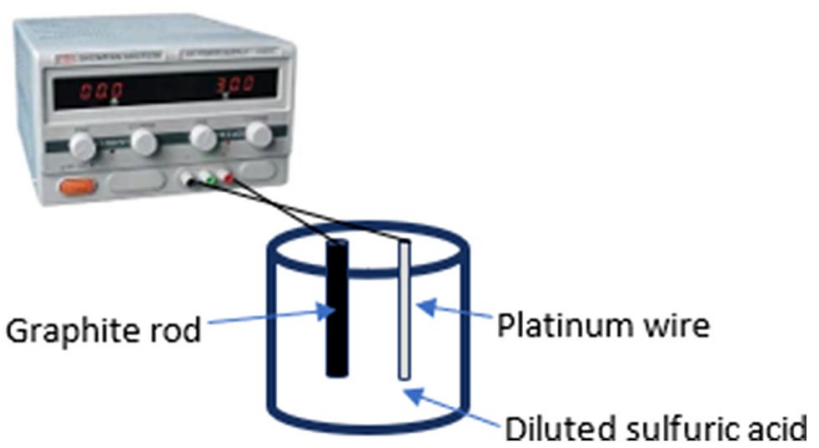

Fig. 1 Electrochemical exfoliation

\subsection{Characterization}

The starting and prepared materials were characterized using optical microscopy, scanning electron microscopy (SEM), X-ray diffraction and Raman spectroscopy.

\subsection{Numerical approach}

COMSOL Multiphysics 5 used to simulate the electrochemical exfoliation of graphite. We used tridimensional model to build the electrochemical exfoliation cell. The dimensions of the graphite rod domain (radius $2 \mu \mathrm{m}$, height $4 \mu \mathrm{m}$ ) and diluted sulfuric acid domain (radius $4 \mu \mathrm{m}$, height $5 \mu \mathrm{m}$ ). We simulated the intercalation of sulfate anions into graphite via transport of diluted species physics using diffusion equations. The physics which used to simulate this phenomenon were transport of diluted species and fluid structure interaction physics to simulate the intercalation and exfoliation processes.

\subsection{Governing equations}

The equations used to model electrochemical exfoliation of graphene based on the diffusion and fluid-structure interaction equations were listed below. Time-dependent study has been chosen in the simulation because of this process based on the time. The migration of sulfate anions through graphite rod under an electrical field. The flow was considered as incompressible and it is represented by the Eqs. (1-2) [41] which shown below.

$\frac{\partial c i}{\partial t}+\nabla \cdot(-D i \nabla c i-z i u m, j F c i \nabla V)+u \cdot \nabla c i=R i$

$N i=(-D i \nabla c i-z i$ um, $j F c i \nabla V)+u \cdot \nabla c i$

where ci: concentration of sulfate anions $(0.1 \mathrm{M})$, Di: diffusion coefficient of sulfates anions $\left(10.6 \times 10^{-8} \mathrm{~m}^{2} / \mathrm{s}\right)$ [42], zi: charge number, u: velocity, V: electrical potential

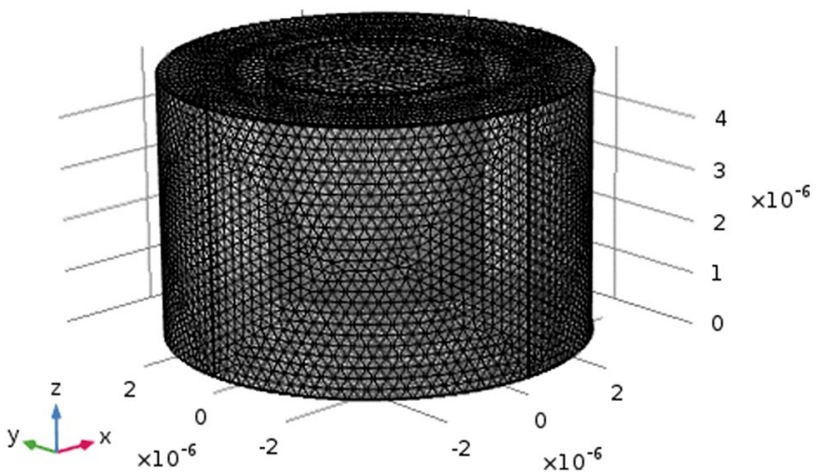

Fig. 2 Meshing of the simulated system

applied to cell $(10 \mathrm{~V}), \mathrm{u}_{\mathrm{m}, j}$ : mobility of sulfate anions. $\mathrm{um}, \mathrm{j}=\frac{D i}{R T}$, (where R: universal gas constant and $\mathrm{T}$ : absolute temperature).

The Eqs. (3-5) represented fluid-structure interaction [43] showed below

$\rho \frac{\partial \text { ufluid }}{\partial t}+\rho($ ufluid $\cdot \nabla)$ ufluid
$\quad=\nabla \cdot\left[p l+\mu\left(\right.\right.$ Dufluid $\left.\left.+\left(\text { ( }_{\text {ufluid }}\right)^{T}\right)\right]+F$

$\rho \nabla \cdot$ ufluid $=0$

$\rho \frac{\partial^{2} \text { usolid }}{\partial t^{2}}-\nabla \cdot \sigma=F v$

where $\rho$ density $\left(\mathrm{g} / \mathrm{cm}^{3}\right), \mathrm{p}$ is the pressure $(\mathrm{Pa}), \mathrm{u}$ is the velocity $(\mathrm{m} / \mathrm{s}), \mu$ is the dynamic viscosity of sulfate anions (2.42 $\times 10^{-2}$ pa s) [44], v: Poisson's ratio (0.17).

\subsection{Meshing}

The system meshed by using physics-controlled meshing to solve equations numerically. The system meshed finely, and it consists of 322,620 domain elements, 17,146 boundary elements, and 608 edge elements. Figure 2 illustrates the meshing of the simulated system.

\section{Results and discussion}

Figure 3 shows photographs of the graphite electrode before and during the electrochemical exfoliation process. As indicated in Fig. 3b, c, the reactions around graphite rod and platinum wire which included oxidation of graphite to allow sulfate anions intercalation at edge and defect sites to occur. Then followed by a reduction reaction of sulfate anions to release sulfur dioxide $\left(\mathrm{SO}_{2}\right)$ which leads to graphite exfoliation. This process of oxidation and reduction occurred simultaneously during the electrochemical 

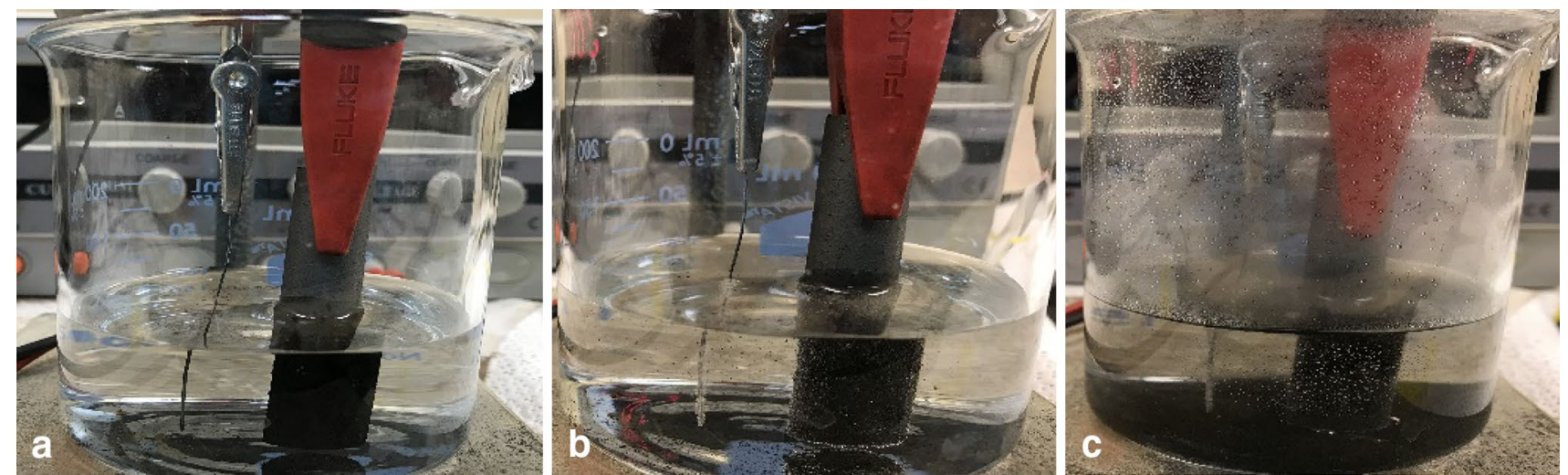

Fig. 3 Photographs for electrochemical exfoliation process: a graphite rod before electrochemical exfoliation. $\mathbf{b}$, c graphite rod during exfoliation process

exfoliation process. Figure 4 shows the graphite rod before and after the exfoliation process using optical microscope. As shown in Fig. $4 \mathrm{~b}$ the influence of electrochemical exfoliation on the graphite rod because of the intercalation of sulfate anions. Figure 5 shows the morphology of graphite and homemade graphene oxide. As shown in the Fig. $5 \mathrm{a}$ the pristine graphite rod consists of very compacted carbon stacks. Conversely, the graphene oxide is made of well-spaced layered systems in which the interlayer spacing is in the $100 \mathrm{~nm}$ scale (Fig. 5b).

The crystal structure of the graphite and the exfoliated graphene oxide were analyzed by conducting X-ray diffraction (XRD) studies. Figure 6 shows the XRD patterns for the graphite powder and exfoliated graphene oxide. As indicated in the Fig. 6 the graphite powder had sharp peak at $26.4^{\circ}$ with $\mathrm{d}$-spacing for a graphitic structure with a layer spacing $3.37 \AA$ also the pattern involved other peaks at $\left(42.3^{\circ}, 44.4^{\circ}, 54.4^{\circ}, 77.5^{\circ}, 83.6^{\circ}\right)$. As shown in the Fig. 6 , The Exfoliated graphene oxide had the same graphite pattern and appearing a peak at $10.8^{\circ}$ with d-spacing $8.19 \AA$ due to the presence of hydroxyl, epoxy and carboxyl groups. The presence of oxygen groups on graphene materials is beneficial for several applications ranging from the production of composite materials to biosensing $[45,46]$.

Figure 7 illustrated the Raman spectra for graphite rod and exfoliate graphene oxide. The data were normalized and analyzed using origin lab software. The spectrum of the graphite rod showed D, G and 2D bands at 1324, 1570 and $2649 \mathrm{~cm}^{-1}$ respectively. The $D$ peak originates from the breathing mode of six-atom rings and requires a defect for activation, therefore the intensity of the $D$ peak depends on the disorder of the graphene. The 2D peak is the second order of the D peak and the shape of the 2D peak varies with different thicknesses of few layers of graphene sheets. According to Ferrari et al. the evolution of the 2D peak is a clear indication of structural transformation from graphite to graphene heterostructures after electrochemical exfoliation [28]. The $G$ peak represents the $E_{2 g}$ phonons vibration mode in the center of the Brillouin zone of $\mathrm{sp}^{2}$ hybrid carbon atom [28]. Exfoliated graphene oxide spectrum showed shifting of main peaks $D, G$ and $2 \mathrm{D}$ bands at 1340,1585 and $2653 \mathrm{~cm}^{-1}$ and appearing $2 \mathrm{G}$ band at $2910 \mathrm{~cm}^{-1}$. The intensity ratio $\left(\mathrm{I}_{\mathrm{D}} / \mathrm{I}_{\mathrm{G}}\right)$ of graphite and exfoliated graphene oxide was $0.46,1.49$ respectively
Fig. 4 Optical microscopy images for a graphite rod. $\mathbf{b}$ Graphite rod after electrochemical exfoliation process
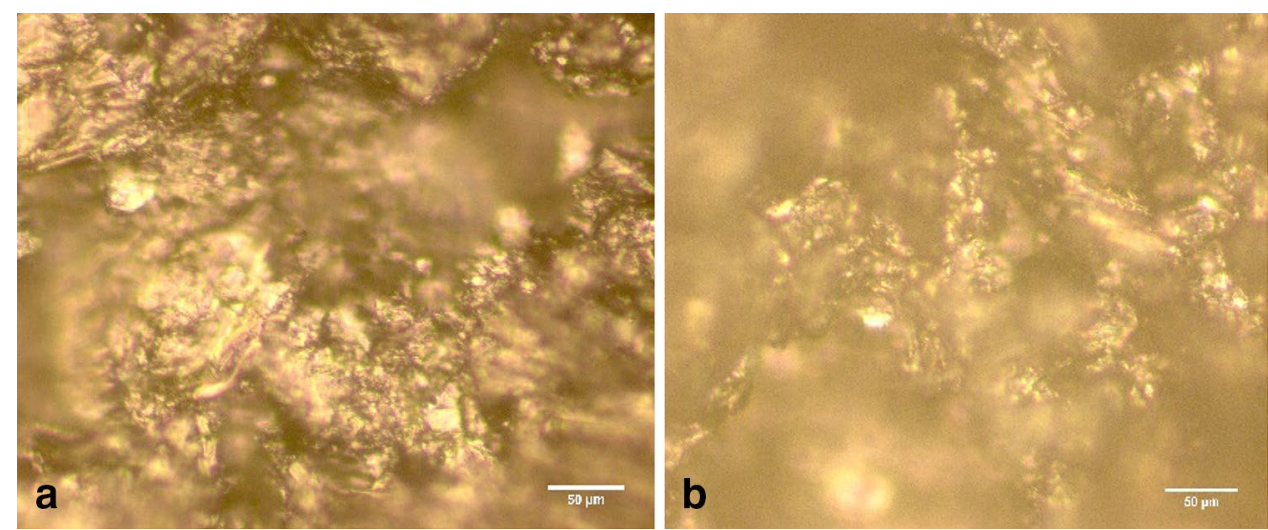

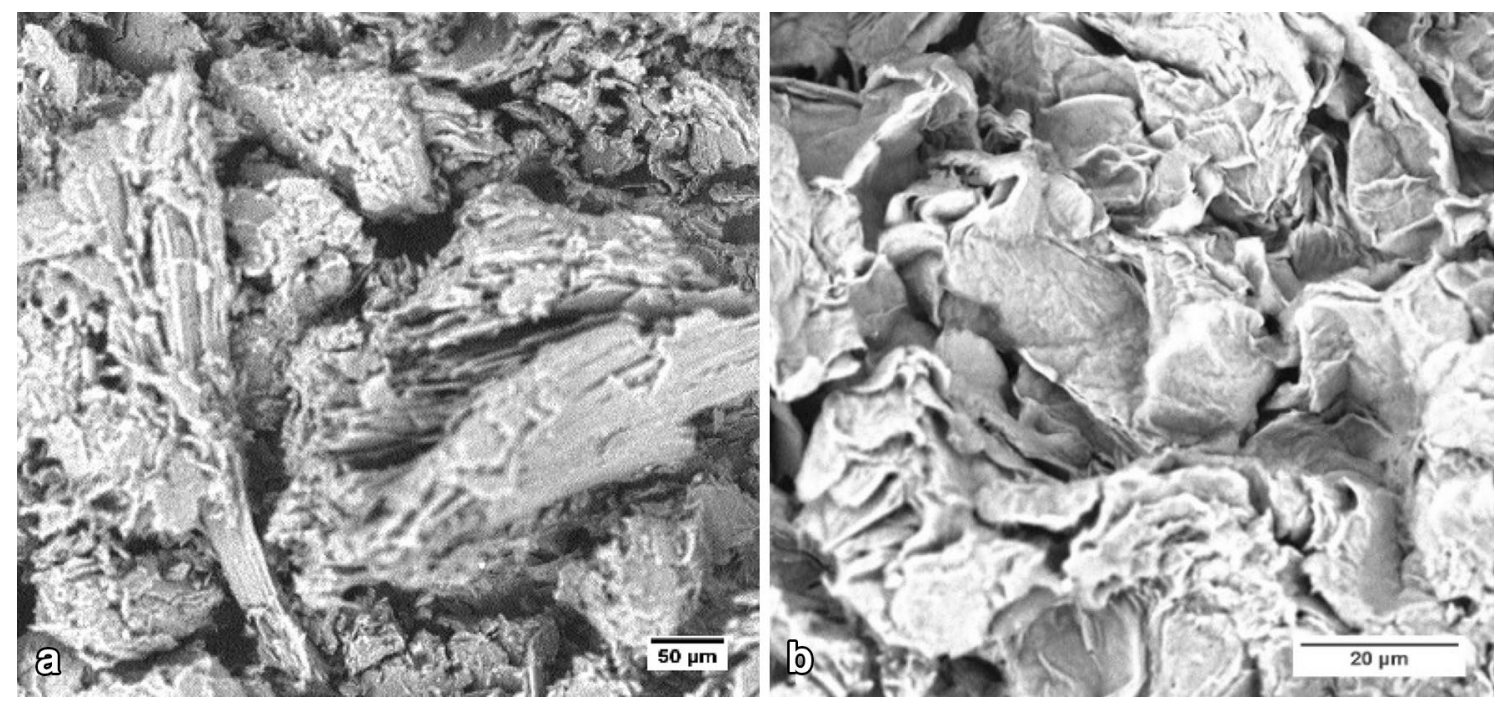

Fig. 5 SEM image for a graphite rod, $\mathbf{b}$ exfoliated graphene oxide

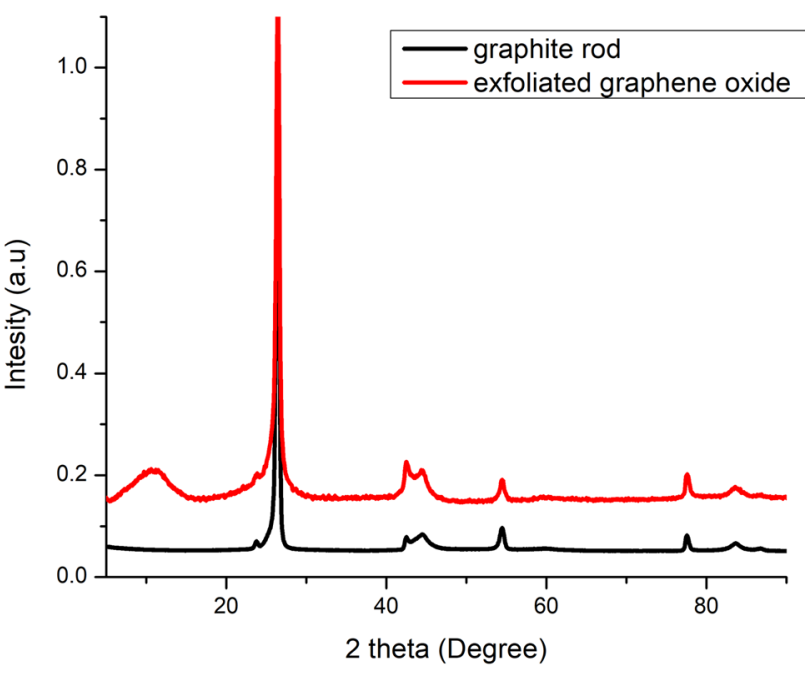

Fig. 6 XRD patterns for graphite rod and exfoliated graphene oxide

as shown in Fig. 7. The intensity ratio can be used to calculate the defects or in-plane crystallite size, calculated according to the Tuinstra-Koenig (TK) relation [47].

$L a=\left(2.1 \times 10^{-10}\right) \lambda^{4}\left(I_{D} / I_{G}\right)^{-1}$

where La is the crystallite sizes, $\lambda$ is the Raman excitation wavelength $(633 \mathrm{~nm})$. The crystallite sizes of graphite and graphene oxide $(\mathrm{La}=73.3 \mathrm{~nm}),(\mathrm{La}=22.8 \mathrm{~nm})$, respectively indicating that the crystallite sizes decreased due to exfoliation of graphite.

On the other side, the intensity ratio of $\left(\mathrm{I}_{2 \mathrm{D}} / \mathrm{I}_{\mathrm{G}}\right)$ indicated the quantity of graphene layers which is 0.22 for exfoliated graphene oxide, that means it is consisted of few layers of graphene. The intensity ratio of $\left(\mathrm{I}_{2 \mathrm{D}} / \mathrm{I}_{\mathrm{G}}\right)$ value is lower than

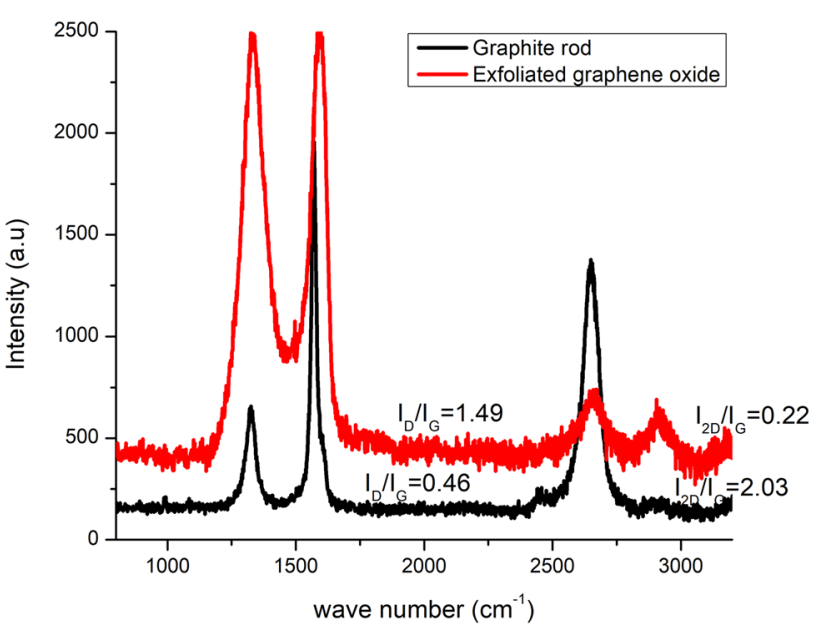

Fig. 7 Raman spectroscopy for graphite rod and exfoliated graphene oxide

other work done by Copper et al. which was 0.68 and they estimated the graphene layers between 2 and 5 layers [27].

The governing equations are solved numerically using finite element method for the meshed system. The results of the simulation showed that the sulfate anions transported and interacted with graphite rod to show the mechanism of electrochemical exfoliation numerically. Figure 8 shows the contours and slices of sulfate anions concentration through graphite rod in the range $\left(9.77 \times 10^{-7}-4.58 \times 10^{-5}\right) \mathrm{mol} / \mathrm{m}^{3}$ which indicated the intercalation of sulfate anions into graphite rod to form graphitic intercalated compounds $\mathrm{C}^{+}\left(\mathrm{SO}_{4}{ }^{2-}\right)$. The concentration gradient of sulfate anions through graphite rod is represented the intercalation of sulfate anions. The results 
Fig. 8 Concentration of sulfate anions through graphite electrode

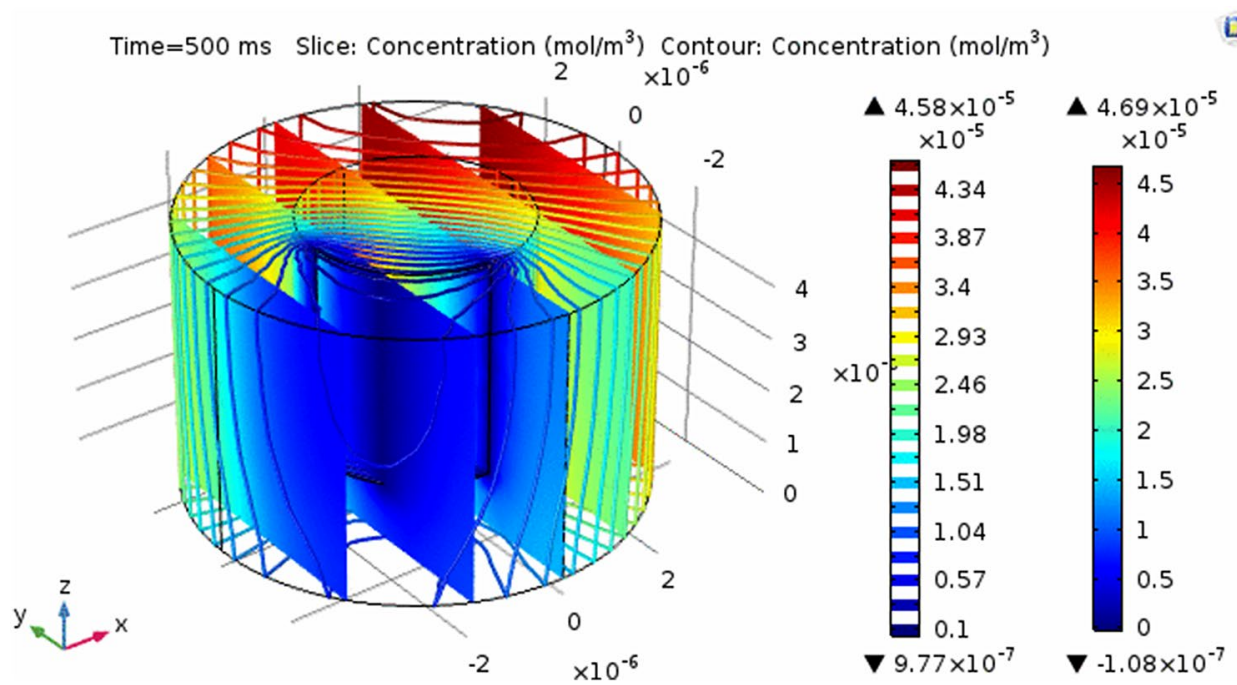

of fluid-structure interaction physics showed that the interaction of sulfate anions along graphite rod.

As shown in Fig. 9 depicts the stresses applied and velocity filed of sulfate anions around graphite rod. The stresses gradient along graphite rod is in the range $\left(3.43 \times 10^{-8}-5.77 \times 10^{-7}\right) \mathrm{N} / \mathrm{m}^{2}$ which is appropriate stress to breakdown the weak van der Waals band between graphene sheets to exfoliate graphite. In previous work which done by Shinde et al. used COMSOL Multiphysics to simulate exfoliation of graphite and they showed that the shear rate played a main role in the exfoliation process [35]. In this study, we presented the full description of the electrochemical exfoliation of graphite numerically and the role of electrolyte in this process. The validation of this simulation is indicated in Fig. 3b, c showed the photographs for graphite rod during the electrochemical exfoliation which totally verified this simulation.

\section{Conclusion}

In summary, graphene oxide prepared using anodically electrochemical exfoliation technique. XRD's pattern for exfoliated graphene oxide indicated appearing a peak at $10.8^{\circ}$ with $\mathrm{d}$-spacing $8.19 \AA$ which is related to graphene oxide and Raman spectrum showed that the intensity ratio $\left(\mathrm{I}_{2 \mathrm{D}} / \mathrm{I}_{\mathrm{G}}\right) 0.22$ therefore the prepared graphene oxide consisted of few layers with crystallite size $22.8 \mathrm{~nm}$. The numerical study indicated that the concentration gradient through graphite rod is in the range $\left(9.77 \times 10^{-7}-4.58 \times 10^{-5}\right) \mathrm{mol} / \mathrm{m}^{3}$ and the magnitude of stresses applied along graphite rod is between $3.43 \times 10^{-8}-5.77 \times 10^{-7} \mathrm{~N} / \mathrm{m}^{2}$.These stresses along graphite rod are appropriate to overcome the weak van der Waals band to exfoliate graphite.
Fig. 9 Stresses applied and velocity field of sulfate anions to the graphite electrode

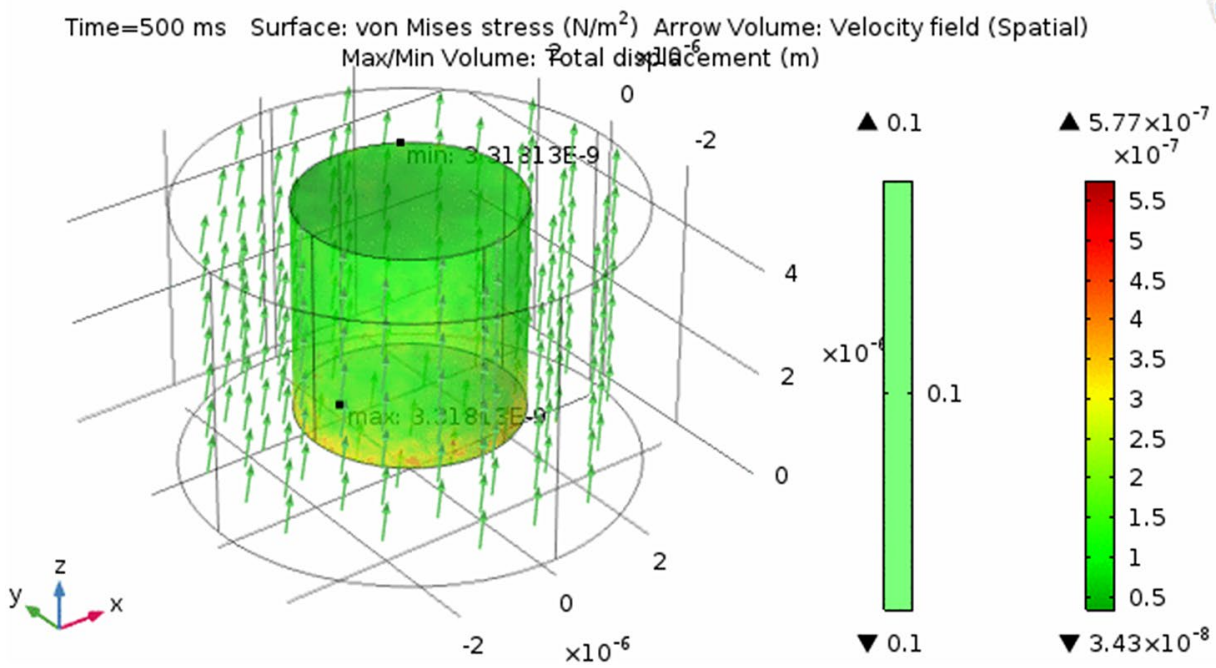




\section{Compliance with ethical standards}

Conflict of interest The author(s) declare that they have no competing interests.

\section{References}

1. Wang Y, Chen X, Zhong Y, Zhu F, Loh KP (2009) Large area, continuous, few-layered graphene as anodes in organic photovoltaic devices. Appl Phys Lett 95:063302

2. Bae S, Kim H, Lee Y et al (2010) Roll- to-roll production of 30-inch graphene films for transparent electrodes. Nat Nanotechnol 5:574

3. Wu D, Zhang F, Liang H, Feng X (2012) Nanocomposite and macrosopic materials: assembly of chemically modified graphene sheets. Chem Soc Rev 18:6141-6160

4. Wu ZS, Parvez K, Feng X, Müllen K (2013) Graphene-based inplane micro- supercapacitor with high power and energy densities. Nat Commun 4:2487-2494

5. Geim AK, Novoselov KS (2007) The rise of graphene. Nat Mater 6:183-191

6. Park S, Ruoff RS (2009) Chemical methods for the production of graphenes. Nat Nanotechnol 4:217-224

7. Bolotin $\mathrm{Kl}$, Sikes KJ, Jiang Z et al (2008) Ultrahigh electron mobility in suspended graphene. Solid State Commun 146:351-355

8. Balandin AA, Ghosh S, Bao W, Calizo I, Teweldebrhan D, Miao F, Lau CN (2008) Superior thermal conductivity of single-layer graphene. Nano Letter 8:902-907

9. Lee C, Wei XD, Kysar JW, Hone J (2008) Measurement of the elastic properties and intrinsic strength of monolayer graphene. Science 321:385-388

10. Chae HK, Siberio-Perez DY, Kim J, Go Y, Eddaoudi M, Matzger AJ, O'Keeffe M, Yaghi OM (2004) A route to high surface area, porosity and inclusion of large molecules in crystals. Nature 427:523-527

11. Nair RR, Blake P, Grigorenko AN, Novoselov KS, Booth TJ, Stauber T, Perse NM, Geim AK (2008) Fine structure constant defines visual transparency of graphene. Science 320:1308

12. Parvez K, Wu Z, Li R, Liu X, Graf R, Feng X, Müllen K (2014) Exfoliation of graphite into graphene in aqueous solutions of inorganic salts. ACS 136:6083-6091

13. Shih CJ, Vijayaraghavan A, Krishnan R, Sharma R, Han JH, Ham $\mathrm{MH}$, Jin Z, Lin SC, Paulus GLC, Reuel NF, Wang QH, Blankschtein D, Strano MS (2011) Bi- and trilayer graphene solutions. Nat Nanotechnol 6:439-445

14. Sutter PW, Flege Jl, Sutter EA (2008) Epitaxial graphene on ruthenium. Nat Mater 7:406-411

15. Singh VV, Gupta G, Batra A, Nigam AK, Boopathi M, Gutch PK, Tripathi BK, Srivastava A, Samuel M, Agarwal GS, Singh B, Vijayaraghavan R (2012) Greener electrochemical synthesis of high quality graphene nanosheets directly from pencil and its SPR sensing application. Adv Funct Mater 22:2352-2362

16. Su C-Y, Lu A-Y, Xu Y, Chen F-R, Khlobystov AN, Li L-J (2011) Highquality thin films from fast electrochemical exfoliation. ACS Nano 5:2332-2339

17. Parvez K, Yang S, Feng X, Mullen K (2015) Exfoliation of graphene via wet chemical route. Synth Met 210:123-132

18. Parvez K, Li RJ, Puniredd SR, Hernandez Y, Hinkel F, Wang SH, Feng XL, Müllen K (2013) Electrochemically exfoliated graphene as solution-processable, highly conductive electrodes for organic electronics. ACS Nano 7:3598-3606

19. Liu N, Luo F, Wu H, Liu Y, Zhang C, Chen J (2008) Onestep ionic-liquid-assisted electrochemical synthesis of ionicliquid-functionalized graphene sheets directly from graphite. Adv Funct Mater 18:1518-1525

20. Kakeai K, Balavandi A (2016) Synthesis of halogen-doped reduced graphene oxide nanosheets as highly efficient metalfree catalyst for oxygen reduction reaction. J Colloid Interface Sci 463:46-54

21. Lee S-H, Seo S-D, Jin Y-H, Shim H-W, Kim D-W (2010) A graphite foil electrode covered with electrochemically exfoliated graphene nanosheets. Electrochem Commun 12:1419-1422

22. Wang J, Manga KK, Bao Q, Loh KP (2011) High-yield synthesis of few-layer graphene flakes through electrochemical expansion of graphite in propylene carbonate electrolyte. ACS 133:8888-8891

23. Alanyalıoğlu M, Segura JJ, Oró-Solè J, Casañ-Pastor N (2012) The synthesis of graphene sheets with controlled thickness and order using surfactant-assisted electrochemical processes. Carbon 50:142-152

24. Morales GM, Schifani P, Ellis G, Ballesteros C, Martínez G, Barbero C, Salavagione HJ (2011) High-quality few layers graphene produced by electrochemical intercalation and microwave-assisted expansion of graphite. Carbon 49:2809-2816

25. Su CY, Lu AY, Xu YP, Chen FR, Khlobystov AN, Li LJ (2011) Highquality thin graphene films from fast electrochemical. ACS Nano 5:2332-2339

26. Wu L, Li W, Li P et al (2014) Powder, paper and foam of fewlayer graphene prepared in high yield by electrochemical intercalation exfoliation of expanded graphite. Small 10:1421-1429

27. Cooper J, Wilson NR, Kinloch IA, Dryfe RAW (2014) Single stage electrochemical exfoliation method for the production of fewlayer graphene via intercalation of tetraalkylammonium cations. Carbon 66:340-350

28. Ferrari C, Meyer JC, Scardaci V, Casiraghi C, Lazzeri M, Mauri F, Piscanec S, Jiang D, Novoselov KS, Roth S, Geim AK (2006) Raman spectrum of graphene and graphene layers. Phys Rev Lett 97:187401

29. Abdelkader AM, Kinloch IA, Dryfe RAW (2014) Continuous electrochemical exfoliation of micrometer-sized graphene using synergistic ion intercalations and organic solvents. ACS Appl Mater Interfaces 6:1632-1639

30. Kakaei K, Zhiani M (2013) A new method for manufacturing graphene and electrochemical characteristics pf graphenesupported Pt nanoparticles in methanol oxidation. J Power Sources 225:356-363

31. Huang X, Li S, Qi Z, Zhang W, Ye W, Fang Y (2015) Low defect concentration few-layer graphene using a two-step electrochemical exfoliation. Nanotechnology 26:105602

32. Kakeai K, Hasanpour K (2014) Synthesis of graphene oxide nanosheets by electrochemical exfoliation of graphite in cetyltrimethylammonium bromide and its application for oxygen reduction. J Mater Chem A 2:15428-15436

33. Ambrosi A, Pumera M (2016) Electrochemically exfoliated graphene and graphene oxide for energy storage and electrochemistry applications. Chem Eur J 22:153-159

34. Najafabadi AT, Gyenge E (2014) High-yield graphene production by electrochemical exfoliation of graphite: novel ionic liquid (IL) - acetonitrile electrolyte with low IL content. Carbon 71:58-69

35. Shinde DB, Brenker J, Easton CD, Tabor RF, Neild A, Majumder M (2016) Shear assisted electrochemical exfoliation of graphite to graphene. Langmuir 32:3552-3559

36. Pupysheva OV, Farajian AA, Knick CR, Zhamu A, Jang BZ (2010) Modeling direct exfoliation of nanoscale graphene platelets. $J$ Phys Chem 114:21083-21087 
37. Yang P, Liu $F$ (2014) Understanding graphene production by ionic surfactant oxidation: a molecular dynamics simulation study. Appl Phys 116(1):014304

38. Shao G, Lu Y, Wu F, Yang C, Zeng F, Wu Q (2012) Graphene oxide: the mechanisms of oxidation and exfoliation. J Mater Sci 47:4400-4409

39. Gai Y, Wang W, Xiao D, Tan H, Lin M, Zhao Y (2018) Exfoliation of graphite into graphene by a rotor-stator in supercritical $\mathrm{CO}_{2}$ : experiment and simulation. Ind Eng Chem Res 57(24):8220-8229

40. Fu G, Yang X (2013) Molecular simulation of interfacial mechanics for solvent exfoliation of graphene from graphite. Carbon 55:350-360

41. COMSOL Multiphysics (2014) Chemical species transport, version 5

42. Vanýsek P (1992) lonic conductivity and diffusion at infinite dilution. CRC Press, Boca Raton, pp 111-113

43. COMSOL Multiphysics (2014) Fluid flow,version 5

44. Lide DR (2005) Handbook of chemistry and physics, 86th edn. CRC Press, Boca Raton
45. Bonanni A, Chua CK, Pumera M (2014) Rational design of carboxyl groups perpendicularly attached to a graphene sheet: a platform for enhanced biosensing applications. Chem Eur J 20:217-222

46. Wang Y, Li Z, Wang J, Li J, Lin Y (2011) Graphene oxide: biofunctionalization and applications in biotechnology. Trends Biotechnol 29:205-212

47. Qi M, Zhou Y et al (2014) Improving terahertz sheet conductivity of graphene films synthesized by atmospheric pressure chemical vapor deposition with acetylene. J Phys Chem C 118:15054-15060

Publisher's Note Springer Nature remains neutral with regard to jurisdictional claims in published maps and institutional affiliations. 